\title{
Investigation of Exclusive Narghile Smokers: Deficiency and Incapacity Measured by Spirometry and 6-Minute Walk Test
}

\author{
Helmi Ben Saad MD PhD, Maya Babba MD, Rafik Boukamcha MSc, Ines Ghannouchi MD, \\ Imed Latiri PhD, Sonia Mezghenni MD, Chakib Zedini MD, and Sonia Rouatbi MD PhD
}

\begin{abstract}
BACKGROUND: Studies on the submaximal aerobic capacity of exclusive narghile smokers (ENS) seem necessary in view of effective prevention of cardiorespiratory diseases. The goal of the study was to assess, by 6-min walk test (6MWT) data, the submaximal aerobic capacity of ENS, to identify factors influencing their 6-min walk distance (6MWD), and to compare their data with those of a healthy non-smoker (HNS) group. METHODS: Seventy 20-60-y-old male ENS were included. Narghile use (narghile-years) and anthropometric, clinical, spirometric, and 6MWT data were collected. Univariate and multivariate analyses were used to identify factors influencing 6MWD. Data of a subgroup of 40-60-y-old ENS $(n=25)$ were compared with those of an age-matched HNS group $(n=53)$. RESULTS: The median (first to third quartile) for age and narghile use were 32 (26-43) and 17 (8-32) narghile-years, respectively. The profile of ENS performing the 6MWT was as follows: at the end of the 6MWT, 34\% and 9\% had a low heart rate $(<60 \%$ of maximum predicted) and high dyspnea scores ( $>5 / 10$, visual analog scale), respectively; $3 \%$ had an oxyhemoglobin saturation decrease of $>5$ points during the test; and $20 \%$ had an abnormal 6MWD (less than the lower limit of the normal range). The factors that significantly influenced the 6MWD, explaining $38 \%$ of its variability, are included in the following equation: 6MWD $(\mathrm{m})=742.63-5.20 \times$ body mass index $\left(\mathrm{kg} / \mathrm{m}^{2}\right)+25.23 \times \mathrm{FEV}_{1}(\mathrm{~L})-0.44 \times$ narghile use (narghile-years). Compared with HNS, the subgroup of ENS had a significantly lower 6MWD $(98 \pm 7$ vs $87 \pm 9 \%$ predicted, respectively). CONCLUSIONS: Narghile use may play a role in reducing submaximal aerobic capacity. The present study suggests that a program of pulmonary rehabilitation is an excellent axis to follow. Key words: smoking; narghile; tabamel; deficiency; incapacity; walk test. [Respir Care 2014;59(11):1696-1709. (C) 2014 Daedalus Enterprises]
\end{abstract}

\section{Introduction}

Tobacco smoking using a narghile is considered a public health threat. ${ }^{1-5}$ It is suspected to be a risk factor for a number of acute and chronic tobacco-related defects and/or diseases. ${ }^{1-8}$

Among the deleterious effects of narghile use, the chronic cardiorespiratory defects are prominent: ${ }^{9-24}$ exclusive narghile smokers (ENS) have been shown to exhibit worse respiratory and cardiac profiles than healthy non-smokers

\footnotetext{
Supplementary material related to this paper is available at http:// www.rcjournal.com.

Dr Ben Saad presented a version of this paper at 20th Annual Congress of the European Respiratory Society, held September 18-22, 2010, in Barcelona, Spain.
}

The authors have disclosed no conflicts of interest 
(HNS) (eg, higher heart rate and systolic (SBP) and diastolic (DBP) blood pressures and lower lung flows and/or volumes). In addition, studies have demonstrated acute (immediate) effects of narghile smoke in the form of increased heart rate, breathing frequency, expired carbon monoxide, SBP, or DBP and a decline in lung function. ${ }^{25-31}$ However, most of these studies ${ }^{9-31}$ have evaluated only changes in basic spirometric and/or cardiac measures at rest.

Although it is important to gauge the effect of narghile smoke exposure on the cardiorespiratory system, resting lung and/or heart function tests may fail to demonstrate the extent of the effect narghile smoke may have on cardiorespiratory function. ${ }^{10,25,32,33}$ Adding to lung and heart function tests by including exercise capacity measures to test the impact of narghile smoke exposure is useful in that more subtle changes or effects that emerge only during stressful or dynamic conditions may then become detectable. ${ }^{10,25,32,33}$ Characterizing such changes can add to a more comprehensive understanding of narghile smoking impact on critical physiological measures, and generated information can serve as a deterrent when counseling smokers against this seemingly harmless habit. ${ }^{10,25,32,33}$

To the best of our knowledge, studies on maximal and submaximal aerobic capacities of ENS are rare:10,25,33 two studies had evaluated the chronic effects of narghile smoke on passive animal smokers ${ }^{33}$ and on human ENS, ${ }^{10}$ and one evaluated its acute effects on human ENS. ${ }^{25}$ Sulai$\operatorname{man}^{33}$ studied an experimental model of pregnant rats exposed to narghile smoke (daily for $10 \mathrm{~min}$ from days 2 to 18 of pregnancy) and examined the effect of smoking on locomotor activity of juvenile rats (ambulatory and stereotype behavior of offspring measured at the age of $30 \mathrm{~d}$ ). He found that the total ambulatory activity and stereotype movements of exposed rats were $21 \%(P=.08)$ and $26 \%$ $(P=.03)$ lower than those of matched controls, respectively, and that the decreased rates of ambulatory activity and stereotype movements in exposed rats were $28 \%$ $(P=.09)$ and 10 -fold $(P<.05)$ lower than those in non-exposed rats, respectively. He concluded that prenatal exposure to narghile smoke lowers the response of offspring to novel environment stimuli.

Koubaa et al ${ }^{10}$ studied the chronic effects of narghile smoking on cardiopulmonary capacities of ENS who performed a triangular test with speed walk. For the ENS group, concerning maximum oxygen uptake $\left(\dot{\mathrm{V}}_{\mathrm{O}_{2}}\right)$ and maximum aerobic speed, statistical analysis showed a signifi-

Correspondence: Helmi Ben Saad MD PhD, Laboratory of Physiology, Faculty of Medicine, University of Sousse, Rue Mohamed Karoui, 4002 Sousse, Tunisia. E-mail: helmi.bensaad@rns.tn.

DOI: $10.4187 /$ respcare. 03058

\section{QUICK LOOK}

\section{Current knowledge}

Smoking flavored tobacco via a water pipe, hookah, or narghile represents a significant public health concern. The impact of this type of smoking on cardiorespiratory function is similar to that seen with traditional cigarette smoking.

\section{What this paper contributes to our knowledge}

Exclusive narghile smokers had a reduced 6-min walk distance compared with an age-matched control of nonsmokers. This reduction in submaximal exercise is an early sign of the progressive negative impact of narghile smoking. Smoking cessation efforts and pulmonary rehabilitation are warranted in this group of smokers as well.

cant difference compared with the exclusive cigarette smoker group. Hawari et $\mathrm{al}^{25}$ characterized the acute effects of narghile smoking on exercise capacity of healthy ENS who performed time-limited cardiopulmonary exercise testing. They used a pilot single-group pre-test (abstained from narghile smoking for $\geq 48 \mathrm{~h}$ ) and post-test (within $0.5 \mathrm{~h}$ of a 45 -min narghile smoking session). After narghile smoking, the carbon monoxide level increased from 3.7 to $24.4 \mathrm{ppm}, \dot{\mathrm{V}}_{\mathrm{O}_{2}}$ decreased from 1.86 to 1.7 $\mathrm{L} / \mathrm{min}$, baseline breathing frequency increased from 17.7 to 19.7 breaths/min, maximum mid-expiratory flow decreased from 5.51 to $5.29 \mathrm{~L} / \mathrm{s}$, and perceived exertion at mid and peak exercise increased. Baseline resting SBP, pulse pressure, and pulse pressure product increased after narghile smoking (from 119 to 129, from 45 to 56, and from 10 to $11 \mathrm{~mm} \mathrm{Hg} / \mathrm{min}$, respectively). During exercise, a decrease in oxygen pulse was observed after narghile smoking (from 11 to $10 \mathrm{~mL}$ of $\mathrm{O}_{2}$ consumed/heartbeat), whereas the heart rate- $\dot{\mathrm{V}}_{\mathrm{O}_{2}}$ relationship increased after narghile smoking from 3.5 to 3.9 beats $/ \mathrm{min} / \mathrm{mL} / \mathrm{kg}$. The authors concluded that acute narghile smoking appears to induce impairment of exercise capacity. ${ }^{25}$

To better explore the chronic effects of narghile use, it would be interesting to refer to the World Health Organization's latest classification of the natural history of chronic diseases (http://www.who.int/classifications/icf/en/, Accessed June 10, 2014), reporting 3 evolutionary stages: deficiency, incapacity, and social disadvantage. The evaluation of incapacity (clinically characterized by dyspnea ${ }^{21}$ ) is considered essential because it alone can predict the future functioning of the patient. This is the determination of exercise tolerance through, for example, data from a field test such as the 6-min walk test (6MWT), which explores the cardiorespiratory and muscle chain. The so- 
cial disadvantage is the psychosocial impact of the disease. This is the assessment of the quality of life. The deficiency has already been extensively explored. ${ }^{7-31}$ The assessment of functional incapacity, for example, through 6MWT data (endurance test, intensity moderately higher than dailyliving activities ${ }^{34,35}$ ), is desirable. Indeed, the skill of walking is a reflection of the ability to maintain a number of daily-life activities for patients. ${ }^{34}$ Therefore, it is an important quality-of-life component. ${ }^{34}$

The present study aimed to add to the current body of literature by evaluating the effects of regular or chronic narghile use on functional capacity utilizing the 6MWT. The main objective of this study, conducted in a population of ENS, was to evaluate their submaximal aerobic capacity through 6MWT data. In addition, the study aimed to compare data from a subset group of ENS (40-60 y) with those of an age-matched HNS control group.

\section{Methods}

The methodology of the present study was previously published as a protocol in progress. ${ }^{32}$

\section{Study Design}

The present cross-sectional study was performed over a 4-month period (January to April 2010) at the Physiology and Functional Exploration Department of the Farhat Hached Hospital in Sousse, Tunisia. Approval for the study was obtained from the ethics committee of the local hospital, and written consent was obtained from all study participants.

\section{Sample Sizes}

ENS Group. The sample size was calculated ${ }^{36}$ as follows:

$$
n=\left(\mathrm{Z}^{2} \times \mathrm{p} \times \mathrm{q}\right) / \Delta^{2},
$$

where $n$ is the number of required ENS, $\mathrm{Z}$ is the $95 \%$ confidence level $(\mathrm{Z}=1.96)$, $\mathrm{q}$ is $1-\mathrm{p}, \Delta$ is precision $(8 \%)$, and $\mathrm{p}$ is the estimation of the 6-min walk distance (6MWD) decline or submaximal aerobic capacity induced by chronic narghile use. Given the pioneering nature of the present work, we referred to a local spirometric study showing that $13 \%(P=.13)$ of ENS have an abnormal $\mathrm{FEV}_{1}\left(\mathrm{FEV}_{1}<\right.$ lower limit of the normal range). ${ }^{16}$ The sample size was thus 68 .

Control Group. Fifty-three 40-60-y-old HNS (neither narghile nor cigarette) were included. Subjects were recruited from the staff of the local faculty of medicine and/or hospital and were also acquaintances of people involved in the study.

\section{ENS Group: Recruitment Method and Inclusion/Non-Inclusion Criteria}

ENS were recruited in 3 ways. We had a database of ENS who had previously participated in studies analyzing their spirometric profiles. ${ }^{17,18}$ We contacted those who met the inclusion criteria. An article was published in a weekly newspaper announcing the need for recruitment of ENS. Informational letters clarifying the aims of the study were then put up at the hospital and the local medical school.

Only male ENS with a $>5$ narghile-year history and $20-60$ y old were included. Detailed non-inclusion criteria were: 6MWT contraindications (unstable angina or myocardial infarction during the previous month, resting heart rate $\geq 120$ beats $/ \mathrm{min}$, resting $\mathrm{SBP} \geq 180 \mathrm{~mm} \mathrm{Hg}$, and resting DBP $\geq 100 \mathrm{~mm} \mathrm{Hg})^{34}$; current or former cigarette or pipe smoking; asthma or recent respiratory infection; diabetes lasting for $>5 \mathrm{y}$; rheumatologic, orthopedic, or surgical diseases interfering with walking; chronic medication use (especially $\beta$ blockers, diuretics, and corticosteroids); imperfect realization of the required maneuvers during spirometry; and inability to perform the 6MWT exactly. ENS had to stop smoking at least $24 \mathrm{~h}$ prior to testing.

\section{Data Collected}

Clinical and sociodemographic characteristics included histories of abdominal surgery, diabetes, dyslipidemia or angina pectoris, coughing and spitting (duration and frequency), dyspnea (Modified Medical Research Council dyspnea scale), obstructive sleep apnea, socioeconomic level, educational level, physical activity scores, sedentary and obesity status, narghile use, and cigarette consumption. Anthropometric data included age (or chronological lung age), weight, height, and body mass index (BMI). Spirometric data included $\mathrm{FVC}, \mathrm{FEV}_{1}$, peak expiratory flow, maximum mid-expiratory flow, $\mathrm{FEV}_{1} / \mathrm{FVC}$, and estimated lung age. 6MWT data included heart rate, oxyhemoglobin saturation, SBP, DBP, dyspnea (visual analog scale), 6MWD, and estimated cardiorespiratory and muscular chain age.

\section{Medical and Physical Activity Questionnaires}

Data were collected using a questionnaire modeled on that of the American Thoracic Society Division of Lung Diseases 78 adult medical questionnaire. ${ }^{37}$ It was composed of questions asked in local Arabic dialect by the same trained operator (MB). This non-validated questionnaire was used to assess several subject characteristics 
(educational level, occupational status, smoking, medical and surgical histories, and medication use).

Cigarette consumption and narghile use were evaluated in pack-years and narghile-years, respectively. ${ }^{3}$ We considered that a smoked narghile contained $25 \mathrm{~g}$ of tobacco (often the tabamel type moassel, unflavored and without glycerol ${ }^{3}$ ), and thus, 1 narghile-year (one narghile/d for $1 \mathrm{y})=9.125 \mathrm{~kg}$ of cumulative tobacco use. ${ }^{3}$

Subjects were classified as coughing if they coughed 4-6 times per d, 4-6 times per week, and as sputum producer if they spit twice per $\mathrm{d}, 4$ or more times per week. ${ }^{37}$

Two educational levels were defined: low (illiterate, primary education) and high (secondary and university education).

Two socioeconomic levels were defined according to occupational status: unfavorable (eg, unskilled worker, jobless) and favorable (eg, skilled worker, farmer, manager). Students were classified according to their parents' occupational status.

Dyspnea was assessed by the Modified Medical Research Council dyspnea scale, ${ }^{38}$ and 2 groups of subjects were identified: no dyspnea (level 1) and dyspnea (levels 2-5).

A translated version of the physical activity questionnaire of Voorrips et al ${ }^{39}$ was filled out by each subject, and household, sporting, and leisure activities were evaluated to yield a total physical activity score. According to the total physical activity score, 2 groups of subjects were defined: sedentary (score $<9.4$ ) and active (score $\geq 9.4$ ).

\section{Physical Examination}

Age (y) was verified by identity cards. Height $( \pm 0.01 \mathrm{~m})$ was measured with a height gauge with shoes removed, heels joined, and back straight. Weight $( \pm 1 \mathrm{~kg}$ ) was measured, and BMI (weight/height ${ }^{2}$ ) was calculated. The following definitions were adopted ${ }^{40}$ : underweight $\left(\right.$ BMI $\left.<18.5 \mathrm{~kg} / \mathrm{m}^{2}\right)$, normal weight $\left(18.5-24.9 \mathrm{~kg} / \mathrm{m}^{2}\right)$, overweight $\left(25.0-29.9 \mathrm{~kg} / \mathrm{m}^{2}\right)$, moderate obesity $(30.0-$ $\left.34.9 \mathrm{~kg} / \mathrm{m}^{2}\right)$, important obesity $\left(35.0-39.9 \mathrm{~kg} / \mathrm{m}^{2}\right.$ ), and morbid obesity (BMI $>40.0 \mathrm{~kg} / \mathrm{m}^{2}$ ). Two groups of subjects were defined: non-obese (BMI $<30.0 \mathrm{~kg} / \mathrm{m}^{2}$ ) and obese (BMI $\geq 30.0 \mathrm{~kg} / \mathrm{m}^{2}$ ).

\section{Electrocardiogram and Spirometry}

A 12-lead resting electrocardiogram was performed at baseline. An abnormal reading was not considered as a reason for excluding subjects.

Spirometric measurements (DATOSPIR-120, Sibel SA, Barcelona, Spain) were performed according to international recommendations. ${ }^{41}$ The results were compared with local reference values. ${ }^{42}$ Spirometric applied definitions were based on the identification of $95 \% \mathrm{CI}$ and therefore the application of the lower limit of the normal range. ${ }^{43} \mathrm{~A}$ large-airway obstructive ventilatory defect was defined as $\mathrm{FEV}_{1} / \mathrm{FVC}$ less than the lower limit of the normal range. A small-airway obstructive ventilatory defect was defined as $\mathrm{FEV}_{1} / \mathrm{FVC}$ more than the lower limit of the normal range, FVC more that the lower limit of the normal range, and maximum mid-expiratory flow less than the lower limit of the normal range. ${ }^{16}$ Depending on the presence of an obstructive ventilatory defect, 2 groups of subjects were retained: no obstructive ventilatory defect and obstructive ventilatory defect. The estimated lung age was calculated. ${ }^{44,45}$ (For additional information about spirometry, see the supplementary materials at http://www.rcjournal. com.)

\section{MWT Procedure, Dyspnea Evaluation, and Applied Definitions}

Only one 6MWT was conducted outdoors according to the American Thoracic Society protocol (for those who are not familiar with conducting a 6MWT). ${ }^{34}$ Subjects were told to eat a light meal, to avoid vigorous exercise in the $2 \mathrm{~h}$ prior to testing, and to wear comfortable clothes and appropriate walking shoes. ${ }^{34}$

The test was conducted along a seldom-traveled, flat, straight corridor (40 m long, marked every $1 \mathrm{~m}$ with cones to indicate turnaround points) with a hard surface. To minimize intraday variability, temperature effects, and biological rhythms, the 6MWT was performed between 2 and $4 \mathrm{PM}$, a period characterized by a stable ambient temperature of $16-20^{\circ} \mathrm{C}$. All subjects performed the $6 \mathrm{MWT}$ for the first time with no warm-up period and no encouragement. However, we specified to each subject that he was allowed to stop and rest during the test.

Each subject sat in a chair located near the starting position for at least $10 \mathrm{~min}$ before the test started. During this time, resting dyspnea, heart rate, oxyhemoglobin saturation (finger pulse oximeter, Nonin, Plymouth, Minnesota), and blood pressures were measured. The test instructions to the subjects were those recommended by the American Thoracic Society. ${ }^{34}$ At the end of the 6MWT, the same data, in addition to 6MWD, were measured. Recommended reasons for immediately stopping the 6MWT include chest pain, intolerable dyspnea, leg cramps, staggering, diaphoresis, and pale or ashen appearance. ${ }^{34}$

In addition to $6 \mathrm{MWD}(\mathrm{m}, \%$ predicted), dyspnea (visual analog scale), SBP and DBP (mm Hg), heart rate (beats/min, $\%$ predicted maximum heart rate), oxyhemoglobin saturation, the difference in oxyhemoglobin saturation before and after the 6MWT, and the number of stops during the 6MWT were noted/calculated.

For subjects 20-40 y old and in the absence of specific local reference values, the predicted 6MWD was calcu- 
lated using the Italian reference values. ${ }^{46}$ For subjects $\geq 40 \mathrm{y}$ old, the predicted 6MWD was calculated according to local reference values. ${ }^{35}$ The 6MWD lower limit of the normal range was calculated by subtracting from the predicted 6MWD value of $89 \mathrm{~m} .{ }^{35}$

Dyspnea during the 6MWT was evaluated by the visual analog scale, which allows an easy evaluation of exercise dyspnea. ${ }^{47}$ Dyspnea was then quantified from 0 (no breathlessness) to 10 (maximum breathlessness). (For additional information about 6MWD reference values and dyspnea evaluation, see the supplementary materials at http:// www.rcjournal.com.)

The following definitions were applied. (1) A 6MWD lower than its lower limit of the normal range was considered a clinically important abnormal value and showed walk intolerance. ${ }^{34,35}$ (2) Stopping during the 6MWT was regarded as an intolerance sign. ${ }^{34,35}$ (3) A difference in oxyhemoglobin saturation before and after the 6MWT of $>5$ points was defined as a clinically important desaturation. ${ }^{35,48}$ (4) An ending dyspnea score of $>5 / 10$ (visual analog scale) was considered clinically important and showed walk intolerance. ${ }^{47,48}$ (5) An ending heart rate of $<60 \%$ predicted was considered a chronotropic insufficiency. ${ }^{35,46}$

Because the 6MWT evaluates the integrated response of the cardiorespiratory and muscular chain, ${ }^{34}$ we calculated, only for subjects $\geq 40 \mathrm{y}$ old, the estimated cardiorespiratory and muscular chain age $(\mathrm{y})^{35}: 140.17-0.19 \times 6 \mathrm{MWD}$ (m) $-0.43 \times$ weight $(\mathrm{kg})+52.92 \times$ height $(\mathrm{m})$.

\section{Description of Narghile}

The narghile is a water pipe that is used to smoke a tobacco preparation (flavored or unflavored) burned by charcoal embers; the smoke is cooled by passing through water before being inhaled. ${ }^{3}$ The different parts of a narghile are indicated in Figure 1. In Tunisia, tabamel is the most popular tobacco for narghile use, ,3,49,50 and one smoked narghile contains an average of 20-30 g of tobacco. (For additional information, see the supplementary materials at http://www.rcjournal.com.)

\section{Statistical Analysis}

Expression Modes of Results. Analysis of the variable distribution was performed using the Kolmogorov-Smirnov test. When the distribution was normal and variances were equal, the results were expressed as mean $\pm \mathrm{SD}$. Otherwise, the results were expressed as the median (first to third quartile) and frequencies for categorical variables. The Student $t$ test was used to compare measured versus predicted data (spirometric and 6MWD values), resting versus ending 6MWT data, and chronological versus estimated ages.

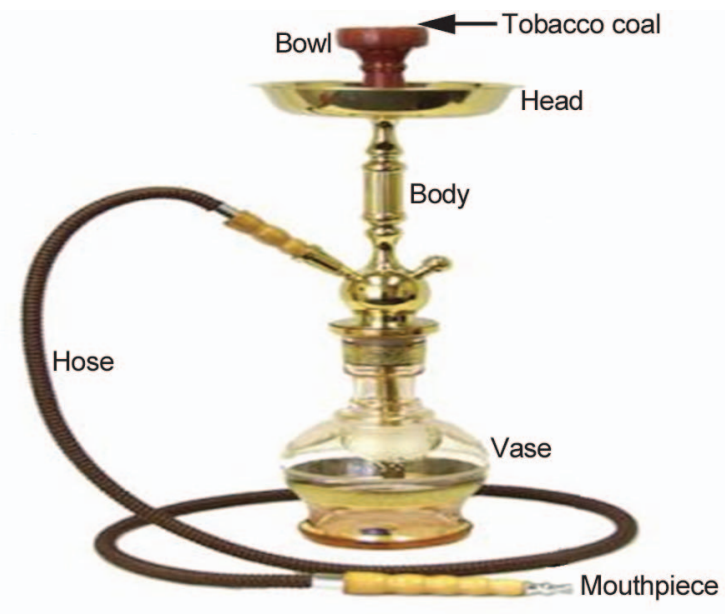

Fig. 1. Parts of the narghile.

Univariate and Multiple Regression Analysis (Influencing Factors). The dependent variable (6MWD) was normally distributed. The $t$ test was used to evaluate the associations between the measured 6MWD and the categorical variables $(0$, no; 1 , yes) for cough, sputum, dyspnea (Modified Medical Research Council dyspnea scale), history of abdominal surgery, sedentary or obesity status, and obstructive ventilatory defect $(0$, unfavorable; 1 , favorable) for socioeconomic level and ( 0 , low; 1 , high) for educational level. Pearson product-moment correlation coefficients ( $r)$ and the determination coefficient $\left(r^{2}\right)$ were used to evaluate the associations between the 6MWD and continuous measures: physical activity scores, narghile use (narghile-years and $\mathrm{kg}$ ), age (y), weight $(\mathrm{kg})$, height $(\mathrm{m})$, BMI $\left(\mathrm{kg} / \mathrm{m}^{2}\right), \mathrm{FEV}_{1}(\mathrm{~L}), \mathrm{FVC}(\mathrm{L}), \mathrm{FEV}_{1} / \mathrm{FVC}$ (absolute value), peak expiratory flow (L/s), maximum mid-expiratory flow (L/s), resting dyspnea (visual analog scale), resting heart rate (beats/min), resting $\mathrm{SBP}(\mathrm{mm} \mathrm{Hg}), \mathrm{DBP}_{\text {rest }}$ $(\mathrm{mm} \mathrm{Hg})$, and resting oxyhemoglobin saturation (\%). The linearity of the association between the 6MWD and the continuous measures was checked graphically by plotting each regressor against the 6MWD. Only significantly and linearly associated variables were entered into the model. A linear regression model was used to evaluate the independent variables explaining the variance in the 6MWD. Candidate variables were stepped into the model with a stepwise selection method. To determine entry and removal from the model, significance levels of .15 and .05 , respectively, were used. No colinearity between predictors was detected with variance inflation factors.

Comparison of ENS Subgroup Versus HNS Data. The $t$ test and chi-square test were used to compare quantitative data and percentages, respectively. A significance threshold of 5\% was retained. Data acquisition and processing 
was performed using Statistica Kernel 6 (StatSoft, Tulsa, Oklahoma).

\section{Results}

\section{ENS Group: Non-Inclusion Criteria and Clinical and Anthropometric Characteristics}

An initial sample of 82 volunteer adults was examined. Non-inclusion criteria were found for 12 subjects. (See the supplementary materials at http://www.rcjournal.com.)

Table 1 presents the characteristics of the 70 ENS. Twenty percent, $23 \%$, and $31 \%$ of the ENS had dyspnea, chronic cough (mean \pm SD duration of $4 \pm 2 \mathrm{y}$ ), and chronic sputum (mean \pm SD duration of $4 \pm 3 \mathrm{y}$ ), respectively. The majority of the ENS had a high school level of education $(82 \%)$ and a favorable socioeconomic level $(67 \%)$. One fourth of the ENS were obese and/or sedentary. In addition, $4 \%$ of the ENS with diabetes mellitus and/or dyslipidemia (duration range of 2-5 y) were medically treated. The minimum-maximum age, weight, height, BMI, and narghile use (narghile-years and $\mathrm{kg}$ ) were 2060 y old, $54-156 \mathrm{~kg}, 1.54-1.90 \mathrm{~m}, 20-50 \mathrm{~kg} / \mathrm{m}^{2}$, and 5-145 narghile-years and 46-1,323 kg, respectively.

The narghile use of the 70 ENS according to 10-y age ranges is shown in Figure 2A. A small percentage of ENS smokers $50-60 \mathrm{y}$ old $(15 \%)$ are included. The 6MWD of the 70 ENS according to narghile use ranges is shown in Figure 2B. A small percentage of the ENS with a $>60$ narghile-year history $(7 \%)$ are included.

\section{ENS Group: Evaluation of Deficiency and Spirometric Profile}

The spirometric data of the 70 ENS (expressed in absolute values and as \% predicted) are presented in Table 1. The measured $\mathrm{FEV}_{1}, \mathrm{FVC}$, and maximum mid-expiratory flow were significantly lower than the predicted values. In addition, $10 \%, 4 \%$, and $35 \%$ of the ENS had $\mathrm{FEV}_{1}$ less than the lower limit of the normal range, a large-airway obstructive ventilatory defect, and a small-airway obstructive ventilatory defect, respectively. The mean \pm SD of the estimated lung age was significantly higher than that of the chronological lung age (44 \pm 3 vs $35 \pm 11 \mathrm{y}$, respectively, $P=.01$ ).

\section{ENS Group: Evaluation of Incapacity}

Comparison of the 6MWT Data. Table 2 presents the $6 \mathrm{MWT}$ data of the 70 ENS. Compared with the resting data, there was a significant increase in the ending heart rate, SBP, DBP, and dyspnea. Oxyhemoglobin saturation was not significantly changed. The measured 6MWD was not significantly different from the predicted 6MWD (mean $\pm \mathrm{SD}$ [minimum-maximum] of $693 \pm 73 \mathrm{~m}(403-$ $837 \mathrm{~m}$ ) versus $101 \pm 14 \%$ predicted ( $64-125 \%$ predicted), $P=.79$ ).

6MWT Profile. No one discontinued the walk or required a rest during the walk. Three percent showed a clinically important desaturation, $9 \%$ expressed clinically important ending dyspnea scores, $20 \%$ had an abnormal $6 \mathrm{MWD}$, and $34 \%$ had a chronotropic insufficiency.

Cardiorespiratory and Muscular Chain Age. The cardiorespiratory and muscular chain estimated age of the 25 ENS $>40$ y old was significantly higher than the chronological age $(65 \pm 12$ vs $47 \pm 6 \mathrm{y}$, respectively, $P<.001)$.

Factors Influencing the 6MWD. Univariate analysis of the 6MWD and ENS data is shown in Table 3. Among the categorical variables, only the sedentary and obesity status significantly affected the 6MWD. The 6MWD significantly correlated with the following continuous variables: narghile use (narghile-years and $\mathrm{kg}$ ), physical activity score, age, weight, BMI, FEV 1 , FVC, peak expiratory flow, maximum mid-expiratory flow, resting SBP, resting DBP, and resting oxyhemoglobin saturation. The independent factors included in the 6MWD forward linear stepwise multiple regressions are listed in Table 4. BMI, $\mathrm{FEV}_{1}(\mathrm{~L})$, and narghile use (narghile-years) together seem to explain 38\% of the 6MWD variability. Figure 3 presents the scatter plot for the 6MWD and narghile use. Heavy ENS had the lowest 6MWD.

Characteristics of ENS Distributed According to the 6MWD (Normal vs Abnormal). Compared with the ENS with a normal 6MWD $(n=56,6 \mathrm{MWD}$ mean \pm SD of $106 \pm 10 \%$ predicted), the ENS with an abnormal 6MWD ( $n=14,6 \mathrm{MWD}$ mean \pm SD of $81 \pm 6 \%$ predicted) had heavier narghile use (55 \pm 44 vs $19 \pm 16$ narghile-years, $P<.001)$; had lower physically active scores $(12 \pm 6$ vs $17 \pm 7, P=.04)$; were older $(45 \pm 7$ vs $32 \pm 10 \mathrm{y}$, $P<.001)$; had a higher BMI $\left(30 \pm 6\right.$ vs $26 \pm 4 \mathrm{~kg} / \mathrm{m}^{2}$, $P=.02)$; showed a marked decline in spirometric data (eg, $\mathrm{FEV}_{1}$ of $84 \pm 14$ vs $94 \pm 11 \%$ predicted, $P=.004$ ); had higher resting heart rates (42 \pm 6 vs $39 \pm 5 \%$ predicted, $P=.04)$, resting SBP $(133 \pm 10$ vs $124 \pm 12 \mathrm{~mm} \mathrm{Hg}$, $P=.009)$, and resting DBP $(85 \pm 9$ vs $78 \pm 10 \mathrm{~mm} \mathrm{Hg}$, $P=.01$ ); and had lower resting oxyhemoglobin saturation $(97 \pm 4$ vs $98 \pm 1 \%, P=.03)$.

\section{Comparison of the 40-60-y-Old ENS Subgroup Versus the HNS Group}

Table 5 presents the characteristics of the subgroup of ENS 40-60 y old $(n=25)$ and the group of HNS subjects 
Table 1. Characteristics of the Exclusive Narghile Smokers

\begin{tabular}{lc}
\hline \hline & Clinical and Sociodemographic Characteristics \\
& $\begin{array}{c}\text { Values, } \\
n(\%)\end{array}$ \\
\hline History of abdominal surgery & $3(15)$ \\
Diabetes mellitus & $3(4)$ \\
History of dyslipidemia & $1(1)$ \\
History of angina pectoris & $16(23)$ \\
Coughing (4-6 times/d, 4-6 times/wk) & $22(31)$ \\
Spitting (2 times/d, $\geq 4$ times/wk) & $14(20)$ \\
Dyspnea (Modified Medical Research Council scale) & $2(2)$ \\
Obstructive sleep apnea & $47(67)$ \\
Favorable socioeconomic level & $58(82)$ \\
High educational level & $14(20)$ \\
Sedentary & $25(36)$ \\
Ideal weight & $30(43)$ \\
Overweight & $12(17)$ \\
Moderate obesity & $1(1)$ \\
Important obesity & $2(2)$ \\
Morbid obesity & $15(21)$ \\
All classes of obesity &
\end{tabular}

Anthropometric Characteristics, Narghile Use, and Physical Activity Scores

Age, median (first to third quartile), y

Weight, median (first to third quartile), $\mathrm{kg}$

$32(26-43)$

Leisure activity score, median (first to third quartile)

$80(70-87)$

Narghile quantity use, median (first to third quartile), narghile-years

$4(3-6)$

Narghile quantity use, median (first to third quartile), $\mathrm{kg}$

$17(8-32)$

Height, mean $\pm \mathrm{SD}, \mathrm{m}$

Body mass index, mean $\pm \mathrm{SD}, \mathrm{kg} / \mathrm{m}^{2}$

$151(73-292)$

Daily activity score, mean \pm SD

Sporting activity score, mean \pm SD

$1.73 \pm 0.06$

$27 \pm 5$

$1 \pm 1$

$9 \pm 6$

Physical Activity Score, Mean \pm SD

$16 \pm 7$

\begin{tabular}{|c|c|c|c|}
\hline \multicolumn{4}{|c|}{ Spirometric Data } \\
\hline & $\begin{array}{l}\text { Absolute Value, } \\
\text { Mean } \pm \text { SD }\end{array}$ & $\begin{array}{l}\% \text { Predicted, } \\
\text { Mean } \pm \text { SD }\end{array}$ & $P$ \\
\hline $\mathrm{FEV}_{1}, \mathrm{~L}$ & $4.02 \pm 0.71$ & $92 \pm 12$ & $<.001 *$ \\
\hline FVC, L & $4.73 \pm 0.87$ & $94 \pm 13$ & $.01 *$ \\
\hline $\mathrm{FEV}_{1} / \mathrm{FVC}$ & $0.85 \pm 0.07$ & $104 \pm 8$ & .06 \\
\hline Peak expiratory flow, $\mathrm{L} / \mathrm{s}$ & $8.82 \pm 1.87$ & $100 \pm 20$ & .97 \\
\hline Maximum mid-expiratory flow, $\mathrm{L} / \mathrm{s}$ & $4.54 \pm 1.19$ & $78 \pm 19$ & $<.001 *$ \\
\hline \multicolumn{4}{|l|}{ Spirometric Profile } \\
\hline & & & $\begin{array}{c}\text { Values, } \\
n(\%)\end{array}$ \\
\hline $\mathrm{FEV}_{1}$ lower than the lower limit of the normal range & & & $7(10)$ \\
\hline Large-airway obstructive ventilatory defect & & & $3(4)$ \\
\hline Small-airway obstructive ventilatory defect & & & $25(35)$ \\
\hline $\begin{array}{l}n=70 . \\
* \text { Student } t \text { test: absolute value versus } \% \text { predicted }\end{array}$ & & & \\
\hline
\end{tabular}

$40-60$ y old $(n=53)$. In summary, compared with the HNS group, the ENS subgroup had significantly lower scores of sporting, leisure, and physical activities; lower ending heart rate, ending SBP, resting DBP, resting oxyhemoglobin saturation, and 6MWD; higher BMI, resting and ending dyspnea scores, resting heart rate, and ending DBP; higher percentages of subjects with low educational levels or sedentary status; and higher estimated cardiorespiratory and muscular chain age $(69 \pm 11$ vs $51 \pm 11 \mathrm{y}$, $P<.001$ and $P<.05$, respectively). It is important to note 
A

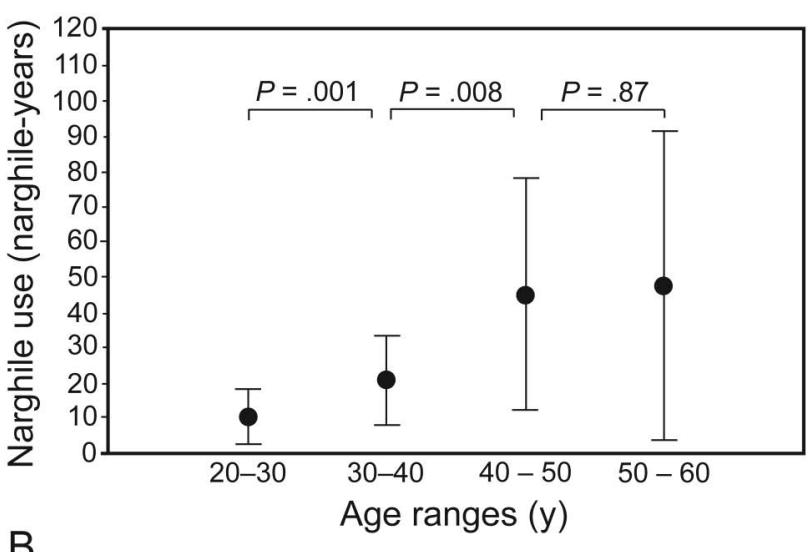

B

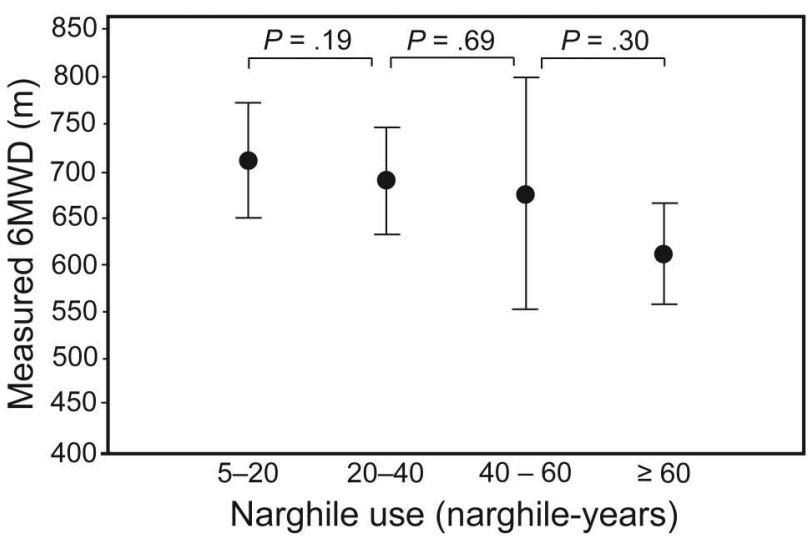

Fig. 2. Data about narghile use. A: Narghile use (expressed in narghile-years) in subgroups of exclusive narghile smokers according to age range. B: Measured 6-min walk distance (6MWD) of subgroups of exclusive narghile smokers according to narghileyears. Data are shown as mean $\pm \mathrm{SD}$.

that no significant statistical difference was found in the spirometric data between the 2 groups.

\section{Discussion}

The main results of the present study involving 70 ENS are that narghile use may play a role in reducing the submaximal aerobic capacity and accelerates the aging of the cardiorespiratory and muscular chain. In addition to quantity of narghile use, a high BMI and a low $\mathrm{FEV}_{1}$ were shown to accelerate the 6MWD decline in the ENS group. Compared with HNS subjects, the ENS subgroup had a significantly lower $6 \mathrm{MWD}(87 \pm 9$ vs $98 \pm 7 \%$ predicted, $P<.001)$. This is a serious argument for encouraging narghile use cessation.

\section{Methodology}

For a discussion of the characteristics of the 2 published studies ${ }^{10,25}$ reporting exercise data in ENS, see the supplementary materials at http://www.rcjournal.com.
Type of Study. This cross-sectional study was economical and easy to perform. It required less time than a longitudinal study and provided much useful information. We decided to compare the spirometry and 6MWT values of a subgroup of ENS with those obtained in another group of age-matched HNS. However, it was desirable to include another group of exclusive cigarette smokers ${ }^{10}$ and/or a validation group. ${ }^{25}$

ENS Sample Size. In a previous study analyzing spirometric deficiency, ${ }^{16} 110$ ENS were included. In the present study, in addition to deficiency, incapacity was evaluated in a field test. This required more time and explains the smaller sample size $(n=70)$. However, the sample size in the present study, calculated using a predictive equation ${ }^{36}$ based on the percentage (13\%) of ENS with abnormal $\mathrm{FEV}_{1},{ }^{16}$ seemed satisfactory. This percentage is similar to that found in the present study (10\%). In addition, the ENS sample size was larger than that used in the 2 studies aiming to evaluate the incapacity of ENS $\left(n=22^{10}\right.$ $n=2425$ ). (See the supplementary materials at http:// www.rcjournal.com.)

Questionnaires and Inclusion and Non-Inclusion Criteria. No standardized medical questionnaire was used in the other 2 studies. ${ }^{10,25}$ (See the supplementary materials at http://www.rcjournal.com.) Medical questions that reduced the risk of errors were asked in face-to-face. Physical activity was assessed by a standardized questionnaire. ${ }^{39}$ The last is reproducible, and its score is positively correlated with the extent of $24 \mathrm{~h}$ of physical activity quantified by using a pedometer. ${ }^{39}$

The applied non-inclusion criteria are in line with those reported for such studies. (See the supplementary materials at http://www.rcjournal.com.) The high percentage of obese ENS included in the present study (21\%) is similar to that reported by Shafique et al. ${ }^{9}$ In addition, it is known that lung alteration occurs only in cases of significant obesity without recognized pulmonary disease. ${ }^{51}$ In the present study, only 3 ENS presented significant obesity; they were not excluded. It is possible that other criteria not assessed in this study, such as occupational exposure and type of heating used in the home, ${ }^{37}$ could have influenced the present results. However, when answering the medical questionnaire, no ENS reported being followed by an occupational physician.

Some precautions were taken during this study. The 6MWT contraindications, which increase the risk of arrhythmia or collapse, were applied as non-inclusion criteria. ${ }^{34}$ To avoid misinterpretation, only male and currently clinically stable ENS were included. As in the other 2 studies, ${ }^{10,25}$ females were not included, despite the fact that the narghile phenomenon is affecting more and more women (69\% of Kuwait females are ENS ${ }^{52}$ ). (See the sup- 
Table 2. 6-Min Walk Test Data for Exclusive Narghile Smokers

\begin{tabular}{|c|c|c|c|}
\hline & Resting & Ending & $P$ \\
\hline Heart rate, mean $\pm \mathrm{SD}$, beats $/ \mathrm{min}$ & $73 \pm 9$ & $121 \pm 22$ & $<.001^{*}$ \\
\hline Heart rate, mean $\pm \mathrm{SD}, \%$ predicted & $40 \pm 5$ & $66 \pm 12$ & $<.001 *$ \\
\hline Oxyhemoglobin saturation, median (first to third quartile), $\%$ & $98(97-98)$ & $98(97-98)$ & .59 \\
\hline Systolic blood pressure, median (first to third quartile), $\mathrm{mm} \mathrm{Hg}$ & $120(120-130)$ & $150(140-160)$ & $<.001 *$ \\
\hline Diastolic blood pressure, median (first to third quartile), $\mathrm{mm} \mathrm{Hg}$ & $80(70-85)$ & $90(80-100)$ & $<.001 *$ \\
\hline Dyspnea score (visual analog scale), median (first to third quartile) & $0(0-0)$ & $2(1-3)$ & $<.001 *$ \\
\hline $6 \mathrm{MWD}$, mean $\pm \mathrm{SD}, \mathrm{m}$ & \multicolumn{2}{|c|}{$693 \pm 73$} & \\
\hline $6 \mathrm{MWD}$, mean $\pm \mathrm{SD}, \%$ predicted & \multicolumn{2}{|c|}{$101 \pm 14$} & $.77 \dagger$ \\
\hline $\begin{array}{l}n=70 . \\
* \text { Student } t \text { test: resting versus ending } \\
\dagger \text { Student } t \text { test: 6-min walk distance (6MWD; m) versus 6MWD (\% predicted) }\end{array}$ & & & \\
\hline
\end{tabular}

plementary materials at http://www.rcjournal.com.) In fact, their inclusion could lead to a diagnosis bias for COPD, for example. ${ }^{53}$ As the average age of initiation into narghile use is $19 \pm 5 \mathrm{y}^{54}$ and as narghile use of $>5$ narghileyears ${ }^{10}$ was set as an inclusion criterion, only ENS $>20 \mathrm{y}$ old were included. However, this narghile phenomenon affects more and more teenagers. ${ }^{49,50}$ As life expectancy in healthy Tunisians was 61 y in 2003, we were unlikely to find ENS over 60 y old who were free of comorbidity and clinically stable. This explains the application of $60 \mathrm{y}$ as an upper age limit. The mean age of ENS (35 y) was intermediate between those of the other 2 studies $\left(20 \mathrm{y}^{25}\right.$ and $\left.45 \mathrm{y}^{10}\right)$. To avoid potential confounding effects, smokers with a history of asthma were not included..$^{55}$ Some other criteria were applied by Hawari et al, ${ }^{25}$ such as abnormal hemoglobin $(<12.5 \mathrm{~g} / \mathrm{dL})$, resting oxyhemoglobin saturation $<96 \%$, and fever. (See the supplementary materials at http://www.rcjournal.com.)

Narghile Tobacco Types. Information about the type of tobacco used was lacking in previous studies. ${ }^{10,25}$ The tobacco used for a narghile weighs between 20 and $30 \mathrm{~g}^{3,16}$ (and not $10-25 \mathrm{~g}$ as stated by Koubaa et $\mathrm{al}^{10}$ ) and is available in 3 main types ${ }^{1}$ : tabamel, tombak, and jurak. Tabamel (Latin tob for tobacco and mel for honey) or moassel (also maasel; sweet, mostly used in Tunisia ${ }^{16}$ ) contains $30 \%$ tobacco and $70 \%$ molasses/honey/glucose syrup plus glycerol and essences. It is much less strong than jurak (nicotine) and is often flavored (apple, strawberry, banana, etc). (For detailed information on tombak and jurak, see the supplementary materials at http:// www.rcjournal.com.) Because narghiles are most often smoked in groups in relatively confined areas, such as cafés and tearooms, the actual amount of smoke inhaled is underestimated. ${ }^{3}$ In addition, as ENS are in this environment everyday for at least $100 \mathrm{~min}$, they become passive smokers at the same time. ${ }^{15}$
In this study, we chose to evaluate submaximal aerobic capacity using the 6MWT data. (For our justification and for precautions taken during the test, see the supplementary materials at http://www.rcjournal.com.)

Applied Definitions for Spirometry and 6MWT Data. International spirometric definitions (based on $95 \% \mathrm{CI}$ ) ${ }^{43}$ and those used in the 6MWT interpretation ${ }^{34,35}$ were applied. The estimated cardiorespiratory and muscular chain age was calculated only for subjects $\geq 40$ y old $(n=25){ }^{35}$ In fact, application of the Italian 6MWD reference values ${ }^{46}$ to this ENS subgroup gave erroneous results.

Study Limitations. Other factors not evaluated in this study may have influenced submaximal aerobic capacity: morphological data (lower limb length, quadriceps strength, muscle biopsy data), biological data (oxidative stress, inflammation, apoptosis, anemia), functional respiratory data (lung volumes, maximum inspiratory and expiratory pressures), blood gas (presence of hypoxemia), diffusion capacity of the alveolar-capillary membrane, measurement of carboxyhemoglobin levels in the blood, and echocardiography data. (For additional information regarding methodology, see the supplementary materials at http:// www.rcjournal.com.)

\section{Outcome}

Evaluation of Deficiency and Spirometric Profile. The spirometric profile of ENS particularly deteriorated in the presence of small-airway obstructive ventilatory defects and acceleration in lung aging. This chronic harmful effect, similar to that induced by cigarette smoking, was described previously in several studies. $7,10,13-22$

Evaluation of Incapacity. Studies on maximal and submaximal aerobic capacities of ENS are rare. (See the supplementary materials at http://www.rcjournal.com.) Kou- 
Deficiency and InCAPacity of Exclusive Narghile Smokers

Table 3. Univariate Analysis of 6-Min Walk Distance and Qualitative or Quantitative Variables

\begin{tabular}{|c|c|c|c|}
\hline Qualitative Variables & Code & Mean \pm SD & $P$ \\
\hline \multirow[t]{2}{*}{ Cough (4-6 times/d, 4-6 times/wk) } & Yes $(n=16)$ & $689 \pm 72$ & .40 \\
\hline & No $(n=54)$ & $707 \pm 76$ & \\
\hline \multirow[t]{2}{*}{ Sputum (2 times/d, $\geq 4$ times/wk) } & Yes $(n=22)$ & $688 \pm 77$ & .39 \\
\hline & No $(n=48)$ & $705 \pm 62$ & \\
\hline \multirow[t]{2}{*}{ Dyspnea (Modified Medical Research Council scale) } & Yes $(n=14)$ & $679 \pm 67$ & .06 \\
\hline & No $(n=56)$ & $699 \pm 74$ & \\
\hline \multirow[t]{2}{*}{ History of abdominal surgery } & Yes $(n=11)$ & $699 \pm 51$ & .76 \\
\hline & No $(n=59)$ & $692 \pm 77$ & \\
\hline \multirow[t]{2}{*}{ Socioeconomic level } & Unfavorable $(n=23)$ & $692 \pm 45$ & .93 \\
\hline & Favorable $(n=47)$ & $694 \pm 84$ & \\
\hline \multirow[t]{2}{*}{ Educational level } & Low $(n=12)$ & $659 \pm 73$ & .06 \\
\hline & $\operatorname{High}(n=58)$ & $701 \pm 71$ & \\
\hline \multirow[t]{2}{*}{ Sedentary status } & Sedentary $(n=14)$ & $646 \pm 89$ & $.005 *$ \\
\hline & Active $(n=56)$ & $705 \pm 64$ & \\
\hline \multirow[t]{2}{*}{ Obesity } & Yes $(n=15)$ & $653 \pm 94$ & $.01 *$ \\
\hline & No $(n=55)$ & $704 \pm 62$ & \\
\hline \multirow[t]{2}{*}{ Large/small-airway obstructive ventilatory defects } & Yes $(n=28)$ & $691 \pm 66$ & .85 \\
\hline & No $(n=42)$ & $695 \pm 77$ & \\
\hline Quantitative Variables & Unit & Correlation Coefficient & $P$ \\
\hline Quantity of tabamel used & Narghile-years & -0.36 & $.002 \dagger$ \\
\hline Physical activity score & & 0.33 & $.004 \dagger$ \\
\hline Age & $\mathrm{y}$ & -0.38 & $<.001 \dagger$ \\
\hline Height & $\mathrm{m}$ & 0.10 & .39 \\
\hline Weight & $\mathrm{kg}$ & -0.48 & $<.001 \dagger$ \\
\hline Body mass index & $\mathrm{kg} / \mathrm{m}^{2}$ & -0.54 & $<.001 \dagger$ \\
\hline $\mathrm{FEV}_{1}$ & $\mathrm{~L}$ & 0.51 & $<.001 \dagger$ \\
\hline FVC & $\mathrm{L}$ & 0.42 & $<.001 \dagger$ \\
\hline Peak expiratory flow & $\mathrm{L} / \mathrm{s}$ & 0.45 & $<.001 \dagger$ \\
\hline Maximum mid-expiratory flow & $\mathrm{L} / \mathrm{s}$ & 0.27 & $.02 \dagger$ \\
\hline $\mathrm{FEV}_{1} / \mathrm{FVC}$ & Absolute value & 0.15 & .22 \\
\hline Resting dyspnea & Visual analog scale & -0.12 & .38 \\
\hline Resting heart rate & & -0.18 & .13 \\
\hline Resting systolic blood pressure & $\mathrm{mm} \mathrm{Hg}$ & -0.35 & $.002 \dagger$ \\
\hline Resting diastolic blood pressure & $\mathrm{mm} \mathrm{Hg}$ & -0.30 & $.01 \dagger$ \\
\hline Resting oxyhemoglobin saturation & $\%$ & -0.48 & $<.001 \dagger$ \\
\hline $\begin{array}{l}n=70 \text { exclusive narghile smokers. } \\
* \text { Student } t \text { test for qualitative variables } \\
\dagger \text { Correlation coefficient for quantitative variables }\end{array}$ & & & \\
\hline
\end{tabular}

Table 4. Independent Factors Included in the 6-Min Walk Distance Forward Linear Stepwise Multiple Regressions

\begin{tabular}{lccc}
\hline \hline \multicolumn{1}{c}{ Independent Factors } & $\begin{array}{c}\text { Non-Standardized } \\
\text { Regression } \\
\text { Coefficient }\end{array}$ & $\begin{array}{c}\text { Cumulated } \\
\text { Determination } \\
\text { Coefficient }\end{array}$ & $P$ \\
\hline Constant & 742.6346 & & $<.001$ \\
Body mass index, $\mathrm{kg} / \mathrm{m}^{2}$ & -5.1969 & 0.2879 & $<.001$ \\
$\mathrm{FEV}_{1}, \mathrm{~L}$ & 25.2326 & 0.3557 & .03 \\
Narghile use, narghile-years & -0.4397 & 0.3796 & .04 \\
& & & \\
\hline$n=70$ exclusive narghile smokers. 6-min walk distance $(\mathrm{m})=742.63-5.20 \times$ body mass \\
index $+25.23 \times \mathrm{FEV}_{1}-0.44 \times$ narghile use.
\end{tabular}

baa et $\mathrm{al}^{10}$ found that an ENS group had a significantly lower maximal $\dot{\mathrm{V}}_{\mathrm{O}_{2}}$ and lower maximum aerobic speed compared with an exclusive cigarette smoker group. Hawari et $\mathrm{al}^{25}$ found that a single session of narghile smoking induced a significant decrease in $\dot{\mathrm{V}}_{\mathrm{O}_{2}}$.

The submaximal aerobic capacity of ENS seemed to deteriorate. Indeed, compared with the HNS group, the subgroup of ENS had a significantly lower 6MWD by $102 \mathrm{~m}$ (see Table 5). In addition, almost one fifth of the ENS had an abnormal 6MWD. Similarly, there were signs of walking intolerance: $3 \%$ and $9 \%$ of the ENS showed a clinically important desaturation and clinically important 


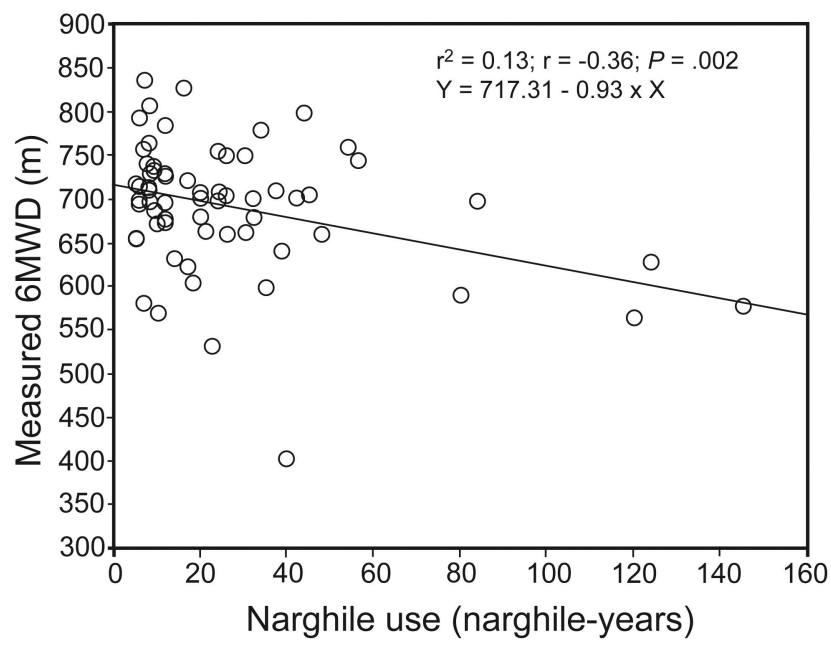

Fig. 3. Scatter plot of 6-min walk distance (6MWD) and narghile use (narghile-years) of 70 exclusive narghile smokers.

ending dyspnea scores, respectively. Another key outcome of the present study is that narghile smoking accelerated cardiorespiratory and muscle chain aging. This is an unwavering argument to motivate ENS to stop smoking. Thirty-four percent of the ENS had an impaired chronotropic heart response. This may reflect the impact of narghile smoking on the activity of the sinus node during walking. ${ }^{26}$ To the best of our knowledge, the present study is the first to determine such chronic effects of narghile use on submaximal aerobic capacity.

\section{How Can We Explain the Impairment of ENS Submaximal Aerobic Capacity?}

The alteration of submaximal aerobic capacity was more pronounced in ENS with a higher BMI, a lower initial $\mathrm{FEV}_{1}$, and/or heavier smoking. These factors are analyzed below.

Effect of BMI. Obesity, especially the morbid type, is predictive of 6MWD decline..$^{34,35}$ In the present study, as in others conducted with healthy subjects, ${ }^{35}$ the $6 \mathrm{MWD}$ decreased by $\sim 5 \mathrm{~m}$ when the BMI increased by 1 unit. Moreover, compared with the HNS subgroup (see Table 5), the ENS subgroup had a significantly higher BMI ( $27 \pm 3$ vs $30 \pm 5 \mathrm{~kg} / \mathrm{m}^{2}$, respectively), with a significantly fewer number of subjects at ideal weight (17 vs $4 \%$, respectively). Similarly, the ENS group with an abnormal 6MWD had a significantly higher BMI compared with the ENS group with a normal $6 \mathrm{MWD}\left(30 \pm 6\right.$ vs $26 \pm 4 \mathrm{~kg} / \mathrm{m}^{2}$, respectively). The present study suggests that the association narghile use-obesity accelerates 6MWD decline. This result is an important argument to encourage ENS to start a diet and/or regular exercise.
Effects of Resting Spirometric Data. Spirometric data are predictors of 6MWD. ${ }^{34,35}$ Indeed, the 6MWD of healthy North Africans decreased by $\sim 12.5 \mathrm{~m}$ when the $\mathrm{FEV}_{1}$ decreased by 1 L. ${ }^{35}$ The present study suggests that the alteration of the resting spirometric data observed in the ENS doubled the 6MWD decline, which was $\sim 25 \mathrm{~m}$. Moreover, the ENS group with an abnormal 6MWD had a significantly lower $\mathrm{FEV}_{1}$ compared with the ENS group with a normal $6 \mathrm{MWD}(84 \pm 14$ vs $94 \pm 11 \%$ predicted, respectively). The alteration of the initial spirometric function limits breathing reserve, ${ }^{48}$ and thus, the lungs may be a factor limiting the 6MWD. 48

Effect of Quantity of Tobacco Use. A higher quantity of tobacco used resulted in a lower 6MWD (see Fig. 3). Similarly, the ENS with an abnormal 6MWD were significantly more engaged in narghile use compared with the ENS with a normal 6MWD (55 \pm 44 vs $19 \pm 16$ narghileyears, respectively). This original result, part of a more general phenomenon, can be explained by the negative consequences of narghile use on cardiorespiratory and muscle functions.

First, it is well established that acute narghile use and chronic narghile use affect resting breathing frequency and lung function data, alter pulmonary epithelial permeability, and accelerate lung aging.7,10,13-21,25,29 An example of an acute effect is that a single 30-min session of narghile smoking induced a significant increase in breathing frequency of $2 \pm 2$ breaths $/$ min. ${ }^{29}$ An example of a chronic effect is that of 110 ENS with a $>1$ narghile-year history, $14 \%$ had small-airway obstructive ventilatory defects, and $6 \%$ had large-airway obstructive ventilatory defects with a significantly higher estimated lung age compared with chronological lung age ( $47 \pm 18$ vs $34 \pm 10 \mathrm{y})$. The present study confirms these findings because the estimated lung age of the ENS group was significantly higher than the chronological lung age, and $35 \%, 9 \%$, and $3 \%$ of the ENS had small-airway obstructive ventilatory defects, clinically important ending dyspnea scores, and a clinically important desaturation, respectively. Similarly, the ENS group with an abnormal 6MWD had lower respiratory data and lower resting oxyhemoglobin saturation compared with the ENS group with an normal 6MWD. In addition, compared with the HNS group, the ENS subgroup 40-60 y old had significantly higher resting and ending dyspnea scores and significantly lower resting oxyhemoglobin saturation (see Table 5).

Second, chronic narghile use and acute narghile use alter the resting cardiac function assessed by heart rate and blood pressure. ${ }^{10,25-31}$ An example of an acute effect is that a single 30 -min session of narghile smoking ( $10 \mathrm{~g}$ of double apple-flavored tabamel) by 45 volunteers induced a significant increase in SBP (from $120 \pm 12$ to $132 \pm 18 \mathrm{~mm} \mathrm{Hg}$ ), DBP (from $75 \pm 8$ to $83 \pm 13 \mathrm{~mm} \mathrm{Hg}$ ), 
Table 5. Comparison of Data From an ENS Subgroup and a Group of HNS Subjects

\begin{tabular}{|c|c|c|c|}
\hline & $\begin{array}{c}\text { ENS } \\
(n=25)\end{array}$ & $\begin{array}{c}\text { HNS } \\
(n=53)\end{array}$ & $P$ \\
\hline \multicolumn{4}{|l|}{ Quantitative variables, mean $\pm \mathrm{SD}$} \\
\hline Quantity of narghile use, narghile-years & $46 \pm 37$ & $0 \pm 0$ & $<.001$ \\
\hline Daily activity & $1.29 \pm 0.65$ & $1.43 \pm 0.59$ & .37 \\
\hline Sporting activity & $3.25 \pm 4.64$ & $7.75 \pm 5.90$ & $<.001 *$ \\
\hline Leisure activity & $2.51 \pm 3.31$ & $5.05 \pm 2.77$ & $<.001 *$ \\
\hline Physical activity & $7.05 \pm 5.62$ & $14.23 \pm 6.73$ & $<.001 *$ \\
\hline Age, y & $47 \pm 6$ & $49 \pm 5$ & .09 \\
\hline Height, m & $1.71 \pm 0.06$ & $1.73 \pm 0.05$ & .09 \\
\hline Weight, kg & $87 \pm 18$ & $82 \pm 8$ & .07 \\
\hline Body mass index, $\mathrm{kg} / \mathrm{m}^{2}$ & $30 \pm 5$ & $27 \pm 3$ & $.01 *$ \\
\hline $\mathrm{FEV}_{1}, \mathrm{~L}$ & $3.46 \pm 0.63$ & $3.54 \pm 0.62$ & .61 \\
\hline $\mathrm{FEV}_{1}, \%$ predicted & $99 \pm 15$ & $100 \pm 12$ & .76 \\
\hline FVC, L & $4.18 \pm 0.76$ & $4.19 \pm 0.74$ & .92 \\
\hline FVC, $\%$ predicted & $97 \pm 15$ & $96 \pm 12$ & 62 \\
\hline Peak expiratory flow, L/s & $7.74 \pm 1.85$ & $8.47 \pm 1.70$ & .09 \\
\hline Peak expiratory flow, $\%$ predicted & $90 \pm 21$ & $98 \pm 19$ & .10 \\
\hline Maximum mid-expiratory flow, $\mathrm{L} / \mathrm{s}$ & $3.90 \pm 1.08$ & $4.20 \pm 1.23$ & .28 \\
\hline Maximum mid-expiratory flow, $\%$ predicted & $98 \pm 28$ & $106 \pm 28$ & .24 \\
\hline $\mathrm{FEV}_{1} / \mathrm{FVC}$, absolute value & $0.83 \pm 0.05$ & $0.85 \pm 0.06$ & .28 \\
\hline Resting dyspnea, visual analog scale & $0.1 \pm 0.3$ & $0.0 \pm 0.0$ & $.008 *$ \\
\hline Ending dyspnea, visual analog scale & $2.3 \pm 1.4$ & $1.0 \pm 0.8$ & $<.001 *$ \\
\hline Resting heart rate, beats/min & $82 \pm 11$ & $74 \pm 9$ & $<.001 *$ \\
\hline Resting heart rate, $\%$ predicted & $47 \pm 6$ & $42 \pm 5$ & $<.001 *$ \\
\hline Ending heart rate, beats/min & $120 \pm 18$ & $154 \pm 19$ & $<.001 *$ \\
\hline Ending heart rate, $\%$ predicted & $69 \pm 10$ & $88 \pm 11$ & $<.001 *$ \\
\hline Resting SBP, mm Hg & $132 \pm 13$ & $129 \pm 18$ & .44 \\
\hline Ending SBP, mm Hg & $157 \pm 19$ & $172 \pm 32$ & $.03 *$ \\
\hline Resting DBP, mm Hg & $85 \pm 10$ & $78 \pm 16$ & $.004^{*}$ \\
\hline Ending DBP, mm Hg & $95 \pm 15$ & $77 \pm 20$ & $<.001 *$ \\
\hline Resting oxyhemoglobin saturation, $\%$ & $97 \pm 3$ & $98 \pm 1$ & $.04 *$ \\
\hline Ending oxyhemoglobin saturation, $\%$ & $97 \pm 4$ & $97 \pm 1$ & .48 \\
\hline $6 \mathrm{MWD}, \mathrm{m}$ & $654 \pm 78$ & $756 \pm 68$ & $<.001 *$ \\
\hline $6 \mathrm{MWD}, \%$ predicted & $87 \pm 9$ & $98 \pm 7$ & $<.001 *$ \\
\hline \multicolumn{4}{|l|}{ Qualitative variables, $n(\%)$} \\
\hline Unfavorable socioeconomic level & $10(40)$ & $30(56)$ & .09 \\
\hline Low educational level & $7(28)$ & $2(4)$ & $<.001 \dagger$ \\
\hline Sedentary & $17(68)$ & $20(37)$ & $.006 \dagger$ \\
\hline Ideal weight & $1(4)$ & $9(17)$ & $.05 \dagger$ \\
\hline Overweight & $15(60)$ & $34(64)$ & .36 \\
\hline Moderate obesity & $7(28)$ & $10(19)$ & .18 \\
\hline Massive obesity & $2(8)$ & $0(0)$ & .02 \\
\hline $\begin{array}{l}\text { * Student } t \text { test } \\
\dagger \text { chi-square test } \\
\text { ENS }=\text { exclusive narghile smokers } \\
\text { HNS }=\text { healthy non-smokers } \\
\text { SBP }=\text { systolic blood pressure } \\
\text { DBP = diastolic blood pressure } \\
6 \text { MWD }=6 \text {-min walk distance }\end{array}$ & & & \\
\hline
\end{tabular}

and heart rate (from $80 \pm 10$ to $96 \pm 17$ beats $/ \mathrm{min}$ ). ${ }^{31} \mathrm{An}$ example of a chronic effect is that the resting heart rate and resting SBP of the 22 ENS with a $>5$ narghile-year history were significantly higher than those of the HNS group $(93 \pm 4$ vs $78 \pm 4$ beats/min and $141 \pm 4$ vs
$131 \pm 3 \mathrm{~mm} \mathrm{Hg}$, respectively). ${ }^{10}$ Thirty-four percent of the ENS had a chronotropic insufficiency, and the ENS group with an abnormal 6MWD had a significantly higher resting heart rate, resting SBP, and resting DBP compared with the ENS group with a normal 6MWD (42 \pm 6 vs 
$39 \pm 5 \%$ predicted, $133 \pm 10$ vs $124 \pm 12 \mathrm{~mm} \mathrm{Hg}$, and $85 \pm 9$ vs $78 \pm 10 \mathrm{~mm} \mathrm{Hg}$, respectively). In addition, the ENS subgroup had a significantly higher resting heart rate and resting DBP compared with the HNS subgroup (see Table 5). The heart rate acceleration and blood pressure increase have harmful effects on submaximal aerobic capacity. ${ }^{56}$

\section{Other Factors Explaining the Submaximal Aerobic Capacity Decline}

The aforementioned factors explain 38\% of the 6MWD variability, which means that $62 \%$ of the variability remains unexplained. What other factors not evaluated in the present study may have affected the 6MWD of the ENS?

We can discuss myopathy as an altering factor of submaximal aerobic capacity: it is likely that the functional, morphological, and metabolic qualities of muscle tissue in ENS are altered. Myopathy could be the result of numerous alterations, with the main ones being sedentary lifestyle, inflammation, apoptosis, oxidative stress, and hypoxia. (See the supplementary materials at http://www. rcjournal.com.)

\section{Conclusion}

Exclusive narghile use may cause an alteration in submaximal aerobic capacity, an adverse effect integrated into a more general phenomenon. To improve submaximal aerobic capacity, a key determinant of quality of life, the results of the present study suggest that a pulmonary rehabilitation program (physical training, weight reduction, narghile use cessation) is an excellent axis to follow. Developing pulmonary rehabilitation policies and measuring their impact in an ENS population are strongly recommended.

\section{ACKNOWLEDGMENTS}

We thank Dr Béchir Saadaoui, freelance translator and proofreader, UPSAT, Sousse, Tunisia, for his invaluable contribution to the improvement of the quality of writing in this paper.

\section{REFERENCES}

1. Chaouachi K. Hookah (shisha, narghile) smoking and environmental tobacco smoke (ETS). A critical review of the relevant literature and the public health consequences. Int $\mathrm{J}$ Environ Res Public Health 2009;6(2):798-843.

2. Chaouachi K. [Narghile (hookah, shisha) and public health]. Tabaccologia 2006;4:29-38. Article in Italian.

3. Ben Saad H. [The narghile and its effects on health. Part I: the narghile, general description and properties]. Rev Pneumol Clin 2009; 65(6):369-375. Article in French.

4. Urkin J, Ochaion R, Peleg A. Hubble bubble equals trouble: the hazards of water pipe smoking. ScientificWorldJournal 2006;6:19901997.
5. Akl EA, Gaddam S, Gunukula SK, Honeine R, Jaoude PA, Irani J. The effects of waterpipe tobacco smoking on health outcomes: a systematic review. Int J Epidemiol 2010;39(3):834-857.

6. Ben Saad H. [The narghile and its effects on health. Part II: the effects of the narghile on health]. Rev Pneumol Clin 2010;66(2): 132-144. Article in French.

7. Raad D, Gaddam S, Schunemann HJ, Irani J, Abou Jaoude P, Honeine R, Akl EA. Effects of water-pipe smoking on lung function: a systematic review and meta-analysis. Chest 2011;139(4):764-774.

8. Knishkowy B, Amitai Y. Water-pipe (narghile) smoking: an emerging health risk behavior. Pediatrics 2005;116(1):e113-e119.

9. Shafique K, Mirza SS, Mughal MK, Arain ZI, Khan NA, Tareen MF, Ahmad, I. Water-pipe smoking and metabolic syndrome: a population-based study. PLoS ONE 2012;7(7):e39734.

10. Koubaa A, Trabelsi H, Masmoudi L, Triki M, Sahnoun Z, Zeghal K, Hakim A. Water pipe tobacco smoking and cigarette smoking: comparative analysis of the smoking effects on antioxidant status, lipid profile and cardiopulmonary quality in sedentary smokers Tunisian. Int J Pharm Sci Invent 2013;2(4):51-57.

11. Mazen A, Aurabia S. The effect of Maassel water-pipe smoking versus cigarette smoking on pulmonary arterial pressure and left ventricular and right ventricular function indices in COPD patients: an echodoppler. Sci J Al Azhar Med Fac 2002;2(1)649-686.

12. Al-Safi SA, Ayoub NM, Albalas MA, Al-Doghim I, Aboul-Enein FH. Does shisha smoking affect blood pressure and heart rate? J Public Health 2009;17(2):121-126.

13. Al Mutairi SS, Shihab-Eldeen AA, Mojiminiyi OA, Anwar AA. Comparative analysis of the effects of hubble-bubble (sheesha) and cigarette smoking on respiratory and metabolic parameters in hubble-bubble and cigarette smokers. Respirology 2006;11(4):449-455.

14. Al-Fayez SF, Salleh M, Ardawi M, Zahran FM. Effects of sheesha and cigarette smoking on pulmonary function of Saudi males and females. Trop Geogr Med 1988;40(2):115-123.

15. Aydin A, Kiter G, Durak H, Ucan ES, Kaya GC, Ceylan E. Waterpipe smoking effects on pulmonary permeability using technetium99m DTPA inhalation scintigraphy. Ann Nucl Med 2004;18(4):285289.

16. Ben Saad H, Khemis M, Bougmiza I, Prefaut C, Aouina H, Mrizek N, et al. Spirometric profile of narghile smokers. Rev Mal Respir 2011;28(7):e39-e51.

17. Ben Saad H, Khemiss M, Bougmiza I, Prefaut C, Aouina H, Mrizek $\mathrm{N}$, et al. [Spirometric profile of narghile smokers]. Rev Mal Respir 2009;26(3):299-314. Article in French.

18. Ben Saad H, Khemiss M, Nhari S, Ben Essghaier M, Rouatbi S. Pulmonary functions of narghile smokers compared with cigarette smokers: a case-control study. Libyan J Med 2013;8:22650.

19. Kiter G, Uçan ES, Ceylan E, Kilinç O. Water-pipe smoking and pulmonary functions. Respir Med 2000;94(9):891-894.

20. Köseoğlu N, Aydin A, Uçan ES, Ceylan E, Eminoğlu O, Durak H, Güven H. The effects of water-pipe, cigarette and passive smoking on mucociliary clearance. Tuberk Toraks 2006;54(3):222-228.

21. Mohammad Y, Kakah M, Mohammad Y. Chronic respiratory effect of narguileh smoking compared with cigarette smoking in women from the East Mediterranean region. Int J Chron Obstruct Pulmon Dis 2008;3(3):405-414.

22. Boskabady MH, Farhang L, Mahmodinia M, Boskabady M, Heydari GR. Comparison of pulmonary function and respiratory symptoms in water pipe and cigarette smokers. Respirology 2012;17(6):950-956.

23. Nemmar A, Raza H, Yuvaraju P, Beegam S, John A, Yasin J, et al. Nose-only water-pipe smoking effects on airway resistance, inflammation, and oxidative stress in mice. J Appl Physiol 2013;115(9): 1316-1323. 


\section{Deficiency and Incapacity of Exclusive Narghile Smokers}

24. Nemmar A, Yuvaraju P, Beegam S, John A, Raza H, Ali BH. Cardiovascular effects of nose-only water-pipe smoking exposure in mice. Am J Physiol Heart Circ Physiol 2013;305(5):H740-H746.

25. Hawari FI, Obeidat NA, Ayub H, Ghonimat I, Eissenberg T, Dawahrah S, Beano $\mathrm{H}$. The acute effects of waterpipe smoking on lung function and exercise capacity in a pilot study of healthy participants. Inhal Toxicol 2013;25(9):492-497.

26. Cobb CO, Sahmarani K, Eissenberg T, Shihadeh A. Acute toxicant exposure and cardiac autonomic dysfunction from smoking a single narghile waterpipe with tobacco and with a "healthy" tobacco-free alternative. Toxicol Lett 2012;215(1):70-75.

27. Blank MD, Cobb CO, Kilgalen B, Austin J, Weaver MF, Shihadeh A, Eissenberg T. Acute effects of waterpipe tobacco smoking: a double-blind, placebo-control study. Drug Alcohol Depend 2011; 116(1-3):102-109.

28. Al-Kubati M, Al-Kubati AS, al'Absi M, Fiser B. The short-term effect of water-pipe smoking on the baroreflex control of heart rate in normotensives. Auton Neurosci 2006;126-127:146-149.

29. Shaikh RB, Vijayaraghavan N, Sulaiman AS, Kazi S, Shafi MS. The acute effects of waterpipe smoking on the cardiovascular and respiratory systems. J Prev Med Hyg 2008;49(3):101-107.

30. Shafagoj YA, Mohammed FI. Levels of maximum end-expiratory carbon monoxide and certain cardiovascular parameters following hubble-bubble smoking. Saudi Med J 2002;23(8):953-958.

31. Hakim F, Hellou E, Goldbart A, Katz R, Bentur Y, Bentur L. The acute effects of water-pipe smoking on the cardiorespiratory system. Chest 2011;139(4):775-781.

32. Ben Saad H, Babba M, Boukamcha R, Latiri I, Knani J, Slama R, et al. Submaximal exercise capacity and quality of life in exclusive water-pipe smokers. Rev Mal Respir 2010;27(5):489-495. Article in French.

33. Sulaiman M. Effects of prenatal exposure to sheesha smoke-response to juvenile rats to novel environment inhalation. Inhal Toxicol 1993; 5(3):313-322.

34. ATS Committee on Proficiency Standards for Clinical Pulmonary Function Laboratories. ATS statement: guidelines for the six-minute walk test. Am J Respir Crit Care Med 2002;166(1):111-117.

35. Ben Saad H, Prefaut C, Tabka Z, Mtir AH, Chemit M, Hassaoune R, et al. 6-Minute walk distance in healthy North Africans older than 40 years: influence of parity. Respir Med 2009;103(1):74-84.

36. Suresh K, Chandrashekara S. Sample size estimation and power analysis for clinical research studies. J Hum Reprod Sci 2012;5(1): 7-13.

37. Ferris BG. Epidemiology Standardization Project (American Thoracic Society). Am Rev Respir Dis 1978;118(6 Pt 2):1-120.

38. Mahler DA, Mackowiak JI. Evaluation of the short-form 36-item questionnaire to measure health-related quality of life in patients with COPD. Chest 1995;107(6):1585-1589.

39. Voorrips LE, Ravelli AC, Dongelmans PC, Deurenberg P, Van Staveren WA. A physical activity questionnaire for the elderly. Med Sci Sports Exerc 1991;23(8):974-979.
40. World Health Organization. Obesity: preventing and managing the global epidemic. Report of a WHO Consultation. World Health Organ Tech Rep Ser. 2000;894:i-xii, 1-253.

41. Miller MR, Hankinson J, Brusasco V, Burgos F, Casaburi R, Coates A, et al. Standardisation of spirometry. Eur Respir J 2005;26(2):319338.

42. Tabka Z, Hassayoune H, Guenard H, Zebidi A, Commenges D, Essabah H, et al. Spirometric reference values in a Tunisian population. Tunis Med 1995;73(2):125-131.

43. Pellegrino R, Viegi G, Brusasco V, Crapo RO, Burgos F, Casaburi $\mathrm{R}$, et al. Interpretative strategies for lung function tests. Eur Respir J 2005;26(5):948-968.

44. Ben Saad H, Elhraiech A, Hadj Mabrouk K, Ben Mdalla S, Essghaier M, Maatoug C, et al. Estimated lung age in healthy North African adults cannot be predicted using reference equations derived from other populations. Egypt J Chest Dis Tuberc 2013;62(4):789-804.

45. Ben Saad H, Selmi H, Hadj Mabrouk K, Gargouri I, Nouira A, Said Latiri H, et al. Spirometric "lung age" estimation for North African population. Egypt J Chest Dis Tuberc 2014;2014;63(2):491-503

46. Chetta A, Zanini A, Pisi G, Aiello M, Tzani P, Neri M, Olivieri D. Reference values for the 6-min walk test in healthy subjects 20-50 years old. Respir Med 2006;100(9):1573-1578.

47. Sergysels R, Hayot M. Evaluation of exercise-induced dyspnea. Rev Pneumol Clin 1997;53(5):278-282.

48. American Thoracic Society, American College of Chest Physicians. ATS/ACCP statement on cardiopulmonary exercise testing. Am J Respir Crit Care Med 2003;167(2):211-277.

49. Harrabi I, Maaloul JM, Gaha R, Kebaili R, Maziak W, Ghannem H. Comparison of cigarette and waterpipe smoking among pupils in the urban area of Sousse, Tunisia. Tunis Med. 2010;88(7):470-473.

50. Ben Saad H, Chaouachi K. Errors and methodological problems in article comparing cigarette and shisha (narghile, hookah, "waterpipe") smoking among pupils in the urban area of Sousse, Tunisia (letter). Tunis Med 2011;89(5):505-506.

51. Doré MF, Orvoën-Frija E. Respiratory function in the obese subject. Rev Pneumol Clin 2002;58(2):73-81.

52. Memon A, Moody PM, Sugathan TN, el-Gerges N, al-Bustan M, al-Shatti A, al-Jazzaf H. Epidemiology of smoking among Kuwaiti adults: prevalence, characteristics, and attitudes. Bull World Health Organ 2000;78(11):1306-1315.

53. Raherison C, Biron E, Nocent-Ejnaini C, Taillé C, Tillie-Leblond I, Prudhomme A. Are there specific characteristics of COPD in women? Rev Mal Respir 2010;27(6):611-624.

54. Tamim H, Terro A, Kassem H, Ghazi A, Khamis TA, Hay MM, Musharrafieh U. Tobacco use by university students, Lebanon, 2001. Addiction 2003;98(7):933-939.

55. Barnes PJ. Mechanisms in COPD: differences from asthma. Chest 2000;117(2 Suppl):10S-14S.

56. Kokkinos P, Manolis A, Pittaras A, Doumas M, Giannelou A, Panagiotakos DB, et al. Exercise capacity and mortality in hypertensive men with and without additional risk factors. Hypertension 2009; 53(3):494-499. 